\title{
A GEOGRAFIA DA INDÚSTRIA DE LANIFÍCIOS NA UNIÃO EUROPEIA ${ }^{1}$
}

\author{
IVA M. PIRES ${ }^{2}$
}

\begin{abstract}
Resumo - Na indústria de lanifícios, ao contrário do que acontece com a do algodão, a concorrência desenvolve-se sobretudo entre países industrializados. A especificidade do produto final, normalmente fabricado em pequenas séries, com incorporação de design e frequentes adaptações à moda, e o seu preço impedem que se destine a um consumo massificado. Por outro lado, a necessidade de mão-de-obra qualificada e experiente não facilita a relocalização da produção para países que apenas têm para oferecer baixos custos de mão-de-obra. A UE continua, assim, a ser o principal produtor de lanifícios destacando-se de entre os países membros, a Itália, Alemanha e a França, que têm igualmente um papel relevante na produção mundial. Um aspecto interessante prende-se com o facto de existir entre estes países uma clara especialização em determinada fase do processo produtivo de lanifícios, trocando preferencialmente entre si os produtos intermédios.

Nos últimos anos não têm parado de crescer os fluxos de produtos da indústria de lanifícios entre os países membros da UE, que continuam a trocar mais entre si do que com o exterior, tornando mais coeso o espaço produtivo, mas sem deixarem de se reforçar, igualmente, a hierarquia definida e a dependência dos países da periferia em relação aos do centro.
\end{abstract}

Palavras-chave: lanifícios, trocas comerciais, UE.

Resumé - LA GEOGRAPHIE DE L'INDUSTRIE LAINIERE DANS L'UNION EUROPEENNE - Dans l'industrie lainière, au contraire de ce qui se passe dans le coton, la concurrence se développe surtout entre pays développés. La spécificité du produit final, normalement fabriqué en petites séries, avec incorporation de design et adaptées à la mode, empêche la consommation massifiée. D'autre part, la nécessité de main d'œuvre qualifiée et expériente gêne la relocalisation de la production dans les pays qui n'ont à offrir que de bas salaires. L'UE mantient sa position de leader de la production mondiale, mais l'Italie, l'Allemagne et la France se détachent parmi eux. Un aspect qu'il est intéressant d'analyser c'est que chacun de ces pays se spécialise dans un segment de la filière de la laine et qu'ils échangent surtout entre eux les produits intermédiaires.

Dans les dernières années, les échanges de produits de lainiers entre les pays de l'UE ont subi un accroissement, ils échangent plus entre eux qu'avec l'extérieur, en rendant plus cohérent l'espace productif mais, en même temps, en renforçant la dépendance des pays de la périphérie par rapport aux pays du centre.

Mots-clés: produits lainiers, échanges comerciaux, UE.

\begin{abstract}
THE GeOGRAPHY OF WOOL TEXTILES IN THE EU - In the wool textiles, unlike cotton, the competition comes mainly from other industrialised countries. The textile specificity, normally produced in small quantities, incorporating design and frequently adapted to fashion, prevents mass consumption. On the other hand the need of qualified and skilled workforce prevents the relocation to countries that can only offer low wages. Thus the EU maintains its world leading position as wool textile producer, the dominant role belonging to Italy, Germany and France. Another important feature is specialisation of each

${ }^{1}$ Este artigo foi efectuado no âmbito do projecto "Desenvolvimento industrial e território", JNICT, $\mathrm{PCSH} / \mathrm{C} / \mathrm{GEO} / 715 / 93$.

2 Professora Auxiliar, Departamento de Sociologia da Universidade Nova de Lisboa. Av. de Berna 26-C, 1000 Lisboa. Tel: 7933519, Fax: 7977759, e-mail: im.pires@fcsh.unl.pt. Investidadora do Centro de Estudos Geográficos.
\end{abstract}


of these countries in a specific segment of the wool filière. In the last years the flows of wool products among the EU countries has been growing and they still trade mostly among them. Consequentely, the productive space has become more cohesive with a simultaneous reinforcement of the centre-periphery model.

Key-words: wool textile, trade, EU.

\section{INTRODUÇÃO}

A União Europeia continua a manter uma posição relevante na produção mundial de fios e tecidos de lã bem como no comércio destes produtos. Só recentemente alguns dos produtores mundiais de lã mais importantes, como a Nova Zelândia, o Uruguai, ou a China, contrariaram esta tendência e conseguiram desenvolver a indústria de lanifícios. $O$ facto de se tratar de uma matéria prima cara, a exigência de mão-de-obra qualificada e o processo de produção longo e complexo resultam num produto que apesar de melhor qualidade é mais caro, destinando-se sobretudo a consumidores com maior poder de compra e mais exigentes em termos de moda. Estes são alguns dos factores que explicam a permanência desta indústria nos países mais industrializados, mantendo-a ao «abrigo da relocalização» que desde os anos 70 tem afectado sobretudo o têxtil de algodão e o vestuário. Mesmo as mais recentes estratégias que a indústria têxtil e do vestuário europeia delinearam para recuperar a competitividade, como a utilização do tráfego de aperfeiçoamento passivo e a subcontratação no exterior (SCHEFFER, 1994; FINE, 1995), não têm, por enquanto, expressão na indústria de lanifícios.

Por outro lado, e ao contrário do que acontece nos outros ramos têxteis, a indústria de lanifícios europeia apresenta um padrão de localização muito concentrado: a Itália contribuiu com mais de metade da produção de fios e tecidos, embora uma atenção crescente deva ser prestada à Alemanha que tem vindo a ganhar uma posição confortável na produção europeia e mundial.

Se tivermos em conta que a maior parte das exportações portuguesas de lanifícios se orientam para o mercado comunitário e que essa dependência tem vindo a aumentar, importa conhecer não só a evolução desta indústria nos outros países membros bem como a nossa posição na produção da UE.

\section{I - EVOLUÇÃO DO EMPREGO}

A população activa na indústria de lanifícios está a sofrer um processo de redução muito acentuado. Ele é particularmente evidente em França e na Espanha onde, em apenas seis anos, esta diminuiu para menos de metade (quadro I).

Quadro I - Pessoal ao serviço na indústria de lanifícios em alguns países da UE, 1988 e 1994 Table I - Wool textile employment in some EU countries, 1988 e 1994

\begin{tabular}{|l|c|c|c|c|c|c|c|c|c|c|c|c|}
\hline & \multicolumn{2}{|c|}{ Benelux } & \multicolumn{2}{c|}{ França } & \multicolumn{2}{c|}{ Itália } & \multicolumn{2}{c|}{ Reino Unido } & \multicolumn{2}{c|}{ Espanha } & \multicolumn{2}{c|}{ Portugal } \\
\hline & 1988 & 1994 & 1988 & 1994 & 1988 & 1994 & 1988 & 1994 & 1988 & 1994 & 1988 & 1994 \\
\hline $\begin{array}{l}\text { Total dos efec- } \\
\text { tivos dos quais: }\end{array}$ & 9400 & 5000 & 23632 & 10498 & 78420 & 66700 & 33403 & 19017 & 23200 & 10825 & 12560 & 11627 \\
\hline Preparação & 1000 & 250 & 4089 & 2184 & 4020 & 3100 & 2546 & 1417 & 1600 & 680 & 660 & 420 \\
\hline Fiação Penteado & 3950 & 3000 & 8594 & 3780 & 29800 & 24600 & 10139 & 4302 & 9700 & 3670 & 4500 & 4200 \\
\hline Fiação Cardado & 2450 & 1500 & 2047 & 1587 & 15400 & 12400 & 10932 & 7048 & 3150 & 1300 & 3500 & 3320 \\
\hline Tecelagem & 2000 & 250 & 5747 & 2974 & 29200 & 26600 & 9786 & 6250 & 8750 & 5175 & 3900 & 3450 \\
\hline
\end{tabular}

Fonte: INTERLAINE. 
Pelo contrário, a evolução do emprego em Portugal, neste período, contrasta com a observada nos outros países. Com efeito, o número de activos a trabalhar nesta indústria quase não sofreu alteração, o que nos coloca, tendo em conta o volume de emprego em 1994, ao nível da França e da Espanha. Porém, a relação emprego/produção é desfavorável: enquanto o emprego nesta indústria significa $9 \%$ do total da UE, a produção portuguesa de lanifícios pouco ultrapassa os $4 \%$ no caso dos tecidos e menos ainda no caso dos fios. Esta é, aliás, uma situação semelhante à do conjunto da indústria têxtil: o peso do emprego nacional no total do emprego na UE é desproporcionado em relação à reduzida relevância na produção.

Contudo, a evolução recente na Beira Interior, onde se localiza a maior parte das empresas produtoras de lanifícios, aponta para valores de emprego mais baixos, tendo em conta que têm vindo a encerrar algumas empresas e que o processo de reestruturação realizado nas outras, que consistiu sobretudo no investimento em novos equipamentos, teve como contrapartida a dispensa de muita mão-de-obra (PIRES, 1994 e 1995).

Considerando a evolução do emprego nas várias fases do processo produtivo, pode observar-se que são afectadas sobretudo as fases a montante, a preparação e fiação, enquanto a tecelagem foi mais poupada. As primeiras fases do processo de produção exigiam muita mão de obra, pelo número de operações necessárias para preparar e fiar a lã. Actualmente, equipamento moderno e sofisticado permite poupar tempo, não só pelo aumento da velocidade de trabalho, mas também porque se pode desenvolver mais do que uma operação em cada máquina.

Se as inovações no equipamento continuarem a surgir, como se espera, a tendência na evolução do emprego só poderá ser a da redução.

\section{II - PRODUÇÃO}

Recuperada a crise dos primeiros anos da década de oitenta, a produção de lanifícios iniciou uma nova fase de crescimento que terminaria, no entanto, ainda na mesma década (fig. 1$)^{4}$. Entre 1990 e 1992 ainda se pode observar uma recuperação no caso dos penteados e tecidos para vestuário, mas a tendência é a da diminuição da produção. No entanto, a UE mantém todos os segmentos de produção da fileira de lanifícios e o saldo da balança comercial permanece positivo.

\footnotetext{
${ }^{3} \mathrm{O}$ concelho da Covilhã foi o mais afectado pelo encerramento de empresas e consequente redução do emprego. O número de activos a trabalhar nesta indústria diminuiu 30\% no concelho, entre 1982 e 1992, e $20 \%$ no Continente (MEES). A reestruturação da indústria de lanifícios, definida pela Portaria n³81/88, foi apoiada pelo Governo que atribuiu 4.6 milhões de contos de incentivos a 44 projectos de investimento executados entre 1988 e 1992. Mais de $80 \%$ do investimento destinou-se à aquisição de equipamento para modernizar o processo produtivo.

4 Os dados utilizados ao longo deste trabalho foram consultados nas estatísticas da INTERLAINE, representada em Portugal pela ANIL, com sede na Covilhã. Estes referem apenas a quantidade (em toneladas) e nunca o valor. Nos quadros de onde foi retirado o total da produção, importação e exportacão da UE e que serviram de base para as figuras, Portugal e Espanha só são contabilizados a partir de 1986, mas na informação desagregada por países já surgem em 1985.
} 


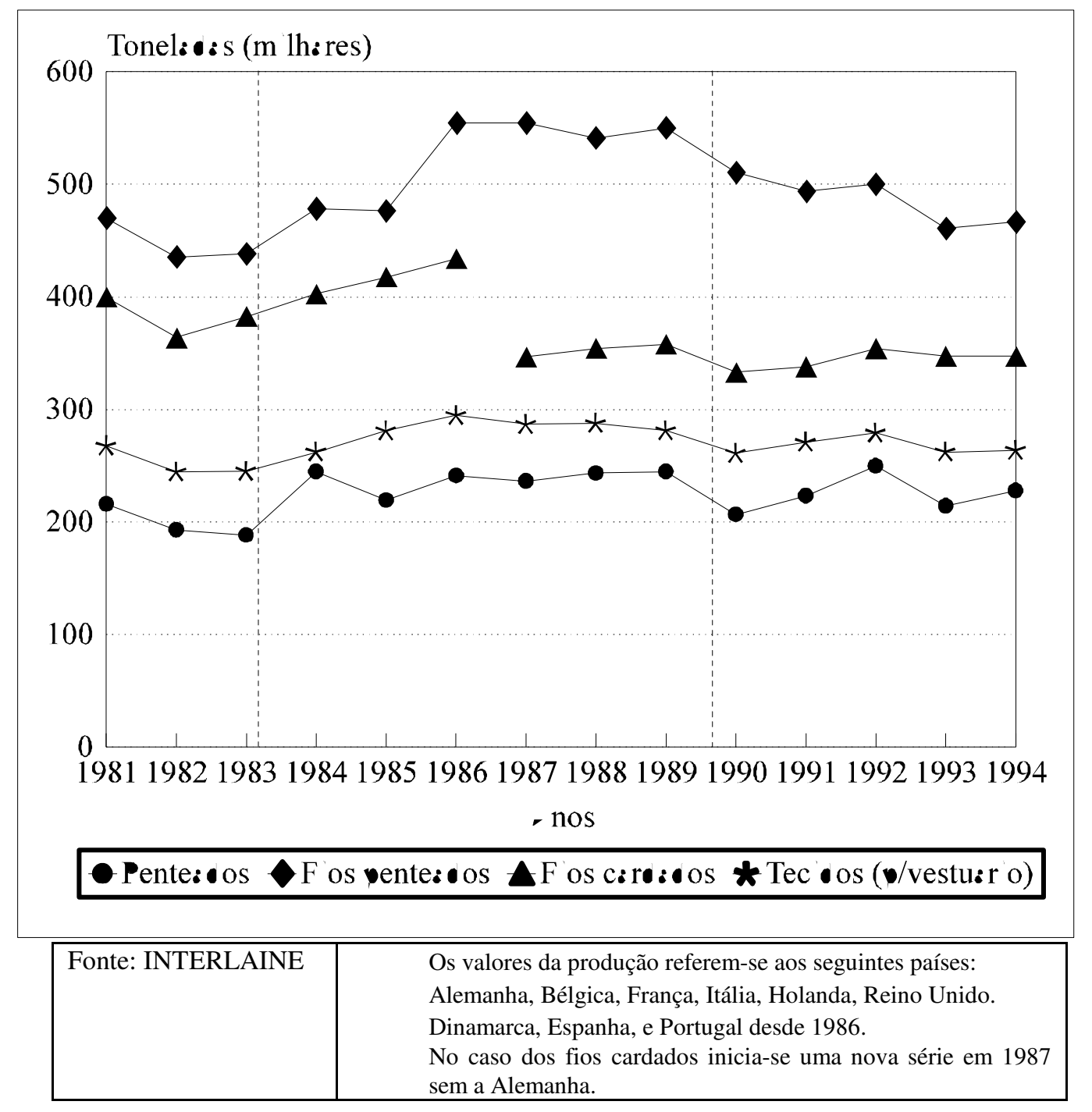

Figura 1 - Produção de lanifícios na UE, 1981-1994.

Figure 1 - EU wool textile production, 1981-1994.

A integração dos países ibéricos deu-se a meio da fase de crescimento e de certa forma contribuiram para o «pico» de produção de 1986, embora o seu contributo tenha sido mais evidente no caso dos fios penteados, já que a Espanha assumiu o segundo lugar na produção da UE.

O volume de produção de 1994 não é muito diferente do do início dos anos oitenta o que mostra, por um lado, que a redução da mão-de-obra, em resultado da modernização do equipamento e do encerramento de empresas, não teve, por enquanto, grandes reflexos sobre a produção, e por outro que a competitividade (baseada não nos preços, mas antes na qualidade e inovação do produto) desta indústria se mantém e a ajuda a minimizar a concorrência de produtores com baixos custos de produção. Significa, também, que existe um volume de procura fiel a estes produtos que permite manter uma produção estável, apesar da concorrência dos de algodão e sintéticos, vendidos a um preço mais acessível.

Se o volume de produção de lanifícios não sofreu grandes alterações ao longo deste período, o mesmo não aconteceu quanto à posição de cada país (quadro II) ${ }^{5}$.

\footnotetext{
${ }^{5}$ Não se inclui a Grécia por não existir informação para este país, nem a Dinamarca e a Holanda porque o seu peso na produção da UE é irrelevante, sendo mesmo inferior ao de Portugal. O total corresponde à participação dos países referidos no quadro.
} 
A Itália é o principal produtor, com excepção dos penteados, e em relação aos principais produtos, fios e tecidos, reforça ainda o seu peso na estrutura da produção da UE nestas últimas décadas. Na realidade, este país representava, em 1994, quase $59 \%$ da produção de fios penteados e semi-penteados para tecelagem e malhas, $60 \%$ da de fios cardados e $63 \%$ da produção de tecidos. A Espanha, o Reino Unido e a Alemanha também se destacam na produção de fios penteados, de fios cardados e de tecidos embora apresentem volumes de produção muito inferiores aos da Itália.

A França, tendo adquirido uma posição de relevo na produção de penteados tem vindo a mostrar crescente dificuldade em a manter. Apesar de continuar a ser o principal produtor, a Itália, em 1994, já apresenta um volume de produção muito próximo do seu enquanto a Alemanha quase duplica a sua desde 1990. Ao mesmo tempo que as empresas francesas perdem competitividade, as alemãs, aproveitando a fragilidade das outras, vão reforçando a sua posição na estrutura da produção da UE. Sendo assim, a Alemanha parece estar a querer definir e consolidar uma nova área de especialização, a dos penteados, tirando partido da quebra da produção observada nos outros países. Por outro lado, tem vindo a reduzir a produção de fios penteados, posição mais difícil de conquistar pois é dominada pelas empresas italianas.

$\mathrm{Na}$ produção de fios nenhum outro país consegue igualar a competitividade das empresas italianas. Estas produzem mais de metade do total da UE e têm vindo a melhorar a sua posição.

$\mathrm{Na}$ estrutura da produção de fios, aqueles que se destinam às malhas têm maior peso do que os que se destinam à tecelagem ${ }^{6}$. Os fios para tricôt, por seu lado, têm vindo a perder importância no conjunto em consequência de um decréscimo da produção de $70 \%$ entre 1986 e 1994. O principal factor apontado para o explicar prende-se com a alteração cultural nos padrões de consumo: por um lado está a perder-se o hábito de fazer malhas à mão, por outro, a indústria das malhas oferece, actualmente, uma grande variedade de produtos atractivos e para todos os preços. Também os jovens tendem a rejeitar as peças de produção doméstica dando mais atenção à marca.

${ }^{6}$ Em 1993 os fios para tecelagem representavam 35.4\% da produção de fios, os destinados às malhas 59.6\% e os de tricôt $5 \%$. 
Quadro II - Estrutura da produção de lanifícios na UE, 1981-1994

Table II - Wool textile production structure in the EU, 1981-1994

\begin{tabular}{|c|c|c|c|c|c|c|c|c|c|}
\hline \multicolumn{5}{|c|}{ Penteados } & \multicolumn{5}{|c|}{ Fios Penteados (a) } \\
\hline Países & 1981 & 1985 & 1990 & 1994 & Países & 1981 & 1985 & 1990 & 1994 \\
\hline Alemanha & 12.9 & 12.0 & 12.5 & 19.2 & Alemanha & 14.4 & 11.3 & 9.0 & 4.8 \\
\hline Bélgica & 7.0 & 6.3 & 7.6 & 1.1 & Bélgica & 7.3 & 6.6 & 7.9 & 5.5 \\
\hline França & 36.5 & 30.5 & 29.2 & 28.5 & França & 16.0 & 11.5 & 7.5 & 6.7 \\
\hline Itália & 25.2 & 23.6 & 25.5 & 26.0 & Itália & 50.7 & 45.5 & 49.8 & 58.7 \\
\hline R. Unido & 18.3 & 18.4 & 16.6 & 17.1 & Holanda & 0.5 & 0.3 & 0.1 & 0.4 \\
\hline Espanha & - & 7.2 & 6.0 & 6.7 & R. Unido & 11.0 & 10.9 & 10.8 & 8.6 \\
\hline \multirow[t]{2}{*}{ Portugal } & - & 2.0 & 2.6 & 1.4 & Espanha & - & 10.8 & 10.9 & 11.6 \\
\hline & & & & & Portugal & - & 3.1 & 3.9 & 3.8 \\
\hline Total (Ton) & 215950 & 241949 & 206751 & 224354 & Total (Ton) & 537411 & 637063 & 541552 & 505472 \\
\hline \multicolumn{5}{|c|}{ Fios Cardados } & \multicolumn{5}{|c|}{ Tecidos para Vestuário } \\
\hline Países & 1981 & 1985 & 1990 & 1994 & Países & 1981 & 1985 & 1990 & 1994 \\
\hline Alemanha & 13.4 & 15.8 & - & - & Alemanha & 15.0 & 14.0 & 15.2 & 12.4 \\
\hline Bélgica & 9.7 & 10.8 & 13.8 & 8.6 & Bélgica & 0.7 & 0.4 & 0.5 & 0.2 \\
\hline França & 9.6 & 7.2 & 5.9 & 5.2 & França & 13.0 & 11.3 & 7.4 & 5.4 \\
\hline Itália & 48.3 & 43.6 & 49.4 & 59.9 & Itália & 59.7 & 55.6 & 57.4 & 62.8 \\
\hline Holanda & 1.1 & 1.0 & 0.6 & 0.0 & Holanda & 1.0 & 0.6 & 0.6 & 1.0 \\
\hline R. Unido & 17.9 & 14.2 & 22.0 & 19.6 & R. Unido & 10.5 & 7.7 & 7.4 & 6.7 \\
\hline Espanha & 0.0 & 4.3 & 4.8 & 3.6 & Espanha & - & 6.6 & 7.5 & 7.1 \\
\hline Portugal & - & 3.2 & 3.5 & 3.0 & Portugal & - & 3.8 & 4.0 & 4.3 \\
\hline Total (Ton) & 399905 & 452015 & 330359 & 346611 & Total (Ton) & $\begin{array}{r}26776 \\
0 \\
\end{array}$ & 313841 & 261319 & 263640 \\
\hline \multicolumn{5}{|c|}{ Cobertores } & & & & & \\
\hline Países & 1981 & 1985 & 1990 & 1994 & & & & & \\
\hline Alemanha & 16.0 & 13.9 (b) & - & - & & & & & \\
\hline Bélgica & 5.7 & 4.4 & 2.3 & 1.9 & & & & & \\
\hline França & 15.7 & 12.3 & 14.9 & 23.8 & Fonte: II & TERLAIN & & & \\
\hline Itália & 56.5 & 34.8 & 35.3 & 54.9 & & & & & \\
\hline R. Unido & 6.1 & 6.0 & 7.7 & 8.4 & & & & & \\
\hline Espanha & - & 25.8 & 33.5 & - & (a) inclui a pr & dução de fic & s para tecel & gem, malh & s e tricôt \\
\hline Portugal & - & 2.7 & 6.3 & 11.1 & (b) $1984 ; \mathrm{de}$ & ois de 1995 & a produçã & $\mathrm{o}$ alemã é c & ontabili- \\
\hline Total (Ton) & 51381 & 45274 & 30455 & 18773 & zada em mill & ares de peç & & & \\
\hline
\end{tabular}

Na produção italiana de fios penteados, em 1994, 71\% correspondem a fios para malhas, valor superior ao da média da UE. As suas malhas são conhecidas pela qualidade e adequação à moda e são, de entre as peças de vestuário, aquelas que têm registado maiores taxas de crescimento do consumo, o que justifica esta situação. Foi precisamente partindo das malhas que a família Benetton construiu um império.

Ao contrário dos outros países, a Alemanha e o Benelux produzem em maior quantidade fios para a tecelagem mas, mesmo em conjunto, apenas atingem metade da produção destes na Itália.

Nos fios cardados a concentração da produção é ainda mais elevada, representando três países, a Itália, o Reino Unido e a Bélgica, quase $89 \%$ do total em $1994^{7}$. Porém, enquanto a Itália reforça consideravelmente a sua posição, nos outros verifica-se uma evolução contrária. A Itália maximiza as vantagens competitivas que também adquiriu na produção deste tipo de fio, continuando a apostar no design e na oferta de um leque muito diversificado de produtos. ${ }^{7}$ A sua importância encontra-se sobrevalorizada uma vez que a Alemanha, o segundo produtor em 1985, não
apresenta dados mais recentes. 
Quanto aos produtos finais, tecidos e cobertores ${ }^{8}$, ambos apresentam uma tendência para a redução da produção, mas no caso destes últimos não é possível avaliar correctamente a evolução da produção uma vez que não existe informação recente para a Espanha, o segundo produtor após a Itália. Por exemplo, em 1990, a sua produção de cobertores foi de 10 mil toneladas, no entanto menos $13 \%$ do que em 1985.

A Itália, para além de ser o principal produtor de fios, particularmente daqueles para o sub-ramo das malhas, também o é nos tecidos e mais uma vez a sua supremacia tem vindo a intensificar-se. O sucesso da indústria de lanifícios neste país decorre da sua flexibilidade, aposta na rápida alteração dos padrões e na produção de pequenas séries o que lhe permite oferecer maior diversidade de produtos. Por outro lado, a produção apoia-se numa rede de pequenas empresas familiares, que têm mais facilidade em tirar partido de segmentos flexíveis de mão-de-obra (mão-de-obra familiar não remunerada, trabalhadores clandestinos, imigrantes) reduzindo assim os custos de produção. A criação de redes de pequenas empresas, onde se desenvolvem as fases mais intensivas em trabalho, resultou do processo de reestruturação iniciado nos anos cinquenta nas grandes empresas têxteis italianas. Estas dispensaram mão-de-obra, modernizaram o equipamento e externalizaram algumas fases do processo produtivo, criando assim a possibilidade de surgirem pequenas empresas, normalmente em nome individual, especializadas na oferta de serviços industriais ${ }^{9}$.

A indústria de lanifícios italiana também se distingue porque é, a par da do Reino Unido, a que continua a incorporar maior quantidade de lã. $\mathrm{Na}$ produção de fios penteados e semi-penteados, por exemplo, a lã representava, em 1994, 43\% das fibras utilizadas, enquanto em Portugal esse valor descia para 33\%. Mas se tivermos em conta que, em 1991, a lã apenas significava $23 \%$ do total das fibras consumidas, esta evolução mostra o empenho da indústria nacional em realizar o upgrading da produção, enquanto a França e a Espanha continuam a utilizar maiores quantidades de fibras químicas.

É na produção de cobertores que Portugal surge com maior destaque na estrutura da produção de lanifícios da UE. Ao mesmo tempo que esta quase duplicava, entre 1985 e 1989, a reorientação das nossas exportações para este mercado foi evidente. Por outro lado, e ao contrário do que está a acontecer na maior parte dos países, a produção portuguesa cresceu cerca de 8\%, entre 1990 e 1994, e já é superior à da Bélgica e à do Reino Unido. Tirando partido da longa tradição na produção e exportação deste produto ${ }^{10}$, Portugal pode definir um nicho de especialização, apesar de a Espanha ser um importante adversário e de não se prever um grande crescimento no consumo devido à concorrência do edredão como produto de substituição.

O mesmo, no entanto, não parece estar a acontecer nos outros segmentos de produção da fileira de lanifícios. Tem vindo a decrescer a produção de fios para malhas, depois de se ter atingido um valor máximo no início da década, o que contraria a evolução verificada nos outros países, com excepção da França, precisamente quando se espera um aumento do consumo destes produtos. Também a produção de cardados sofreu uma redução de cerca de 4000 toneladas, entre 1985 e 1994. Menos mal parece estar o sector da tecelagem, apesar de a produção não ter crescido de forma significativa nos últimos anos, pelo menos tem vindo a recuperar da quebra verificada em meados da década de oitenta.

\footnotetext{
${ }^{8}$ Embora a incorporação de lã seja actualmente menor e mostre tendência para continuar a reduzir-se e o processo de produção seja muito distinto do dos lanifícios, a produção destes bens continua a integrar-se neste ramo. As fibras dominantes são, para todos os países para os quais existe informação, as sintéticas, variando o peso da lã, em 1994, entre 14\% na Alemanha e 44\% na França. O nosso país não publica valores de produção desagregados por fibra dominante.

9 A bibliografia sobre a indústria têxtil italiana e sobre os Distritos Industriais é extensa, salientam-se apenas alguns títulos: ConTini (1988), BAGNASCO (1989), Amin (1989), GAROFOli (1992), BeCATTINI (1992).

10 Durante a II Guerra Mundial Portugal tirou partido do facto de não se ter envolvido directamente no conflito para aumentar a sua produção de têxteis (só limitada pela escassez de matérias primas), nomeadamente de cobertores, que colocava no mercado europeu. No concelho da Guarda localizam-se várias empresas especializadas na produção de cobertores. Estas têm vindo a modernizar o processo de produção, exportando a maior parte para parceiros da UE.
} 
De uma maneira geral, parece que as empresas protuguesas, após um primeiro momento durante o qual conseguiram beneficiar desta nova situação, estão a sentir dificuldade em colocar os seus produtos quer no mercado interno quer no da UE. Se por um lado é compreensível esta situação, pois o processo de reestruturação foi tardio e a crise económica não propiciava grandes investimentos, por outro, contaram com apoios para a modernização da estrutura produtiva e continuaram a beneficiar de baixos custos de mão-de-obra. Poder-se-á considerar que esta representou uma primeira fase, que assentou sobretudo no reequipamento, mas que agora é necessário um segundo esforço de modernização orientado para a inovação do produto, comercialização e para a internacionalização.

\section{III - AS TROCAS COMERCIAIS}

\section{1 - ESPAÇO ECONÓMICO DA UE}

O contributo de cada país para as trocas intra-UE é muito diverso, como se pode observar no quadro III. Três países - Alemanha, Itália e França - repartem entre si a maior fatia, quer nas exportações quer nas importações. Mas enquanto a Itália se distingue como exportador, sendo responsável por $30 \%$ das exportações intra-UE, a Alemanha recebe $22 \%$ dessas trocas, transformando-se num mercado desejável para todos os outros produtores. Apesar disso este país não tem descurado a exportação e, tal como a França, tem vindo a reforçar a sua posição no comércio interno. Os outros países, pelo contrário, excluindo a Espanha que conseguiu tirar partido da sua integração no mercado único aumentando o peso na produção e mantendo a balança comercial positiva, vêem reduzir-se a sua capacidade de intervenção nas trocas de lanifícios. Por outro lado, os pequenos produtores praticamente não estabelecem trocas comerciais entre si, com excepção da Bélgica e da Holanda, preferindo fazê-lo com os principais mercados (fig. 2a e 2b).

Se desagregarmos o tráfego por produtos os mesmos países surgem a dominá-lo na maior parte deles, com excepção dos fios de lã cardada, nos quais o Reino Unido mantém a sua supremacia como principal exportador.

Quadro III - Estrutura das importações e das exportações intra-UE, 1988 e 1994

Table III - Trade balance in EU, 1988 e 1994

\begin{tabular}{|l|r|r|r|r|r|r|}
\hline & \multicolumn{2}{|c|}{ Exportações } & \multicolumn{2}{c|}{ Importações } & \multicolumn{2}{c|}{$\begin{array}{c}\text { Saldo da Balança Co- } \\
\text { mercial (Ton.) }\end{array}$} \\
\hline & \multicolumn{1}{|c|}{1988} & \multicolumn{1}{|c|}{1994} & \multicolumn{1}{c|}{1988} & \multicolumn{1}{c|}{1994} & 1988 & \multicolumn{1}{c|}{1994} \\
\hline França & 21.7 & 22.0 & 14.1 & 14.0 & 25318 & 25207 \\
\hline Benelux & 12.8 & 8.2 & 13.5 & 9.7 & -2426 & -4596 \\
\hline Holanda & 2.8 & 2.5 & 9.6 & 6.4 & -22621 & -12287 \\
\hline Alemanha & 16.2 & 17.6 & 23.0 & 21.9 & -22212 & -13712 \\
\hline Itália & 26.2 & 29.5 & 15.3 & 23.1 & 36175 & 20122 \\
\hline ReinoUnido & 7.4 & 7.4 & 15.0 & 13.0 & -24885 & -17647 \\
\hline Irlanda & 2.6 & 1.7 & 3.2 & 0.0 & -2048 & -1628 a) \\
\hline Dinamarca & 0.9 & 0.6 & 2.8 & 1.6 & -6237 & -2939 \\
\hline Grécia & 1.6 & 0.7 & - & 0.0 & 5264 & $-6760 \mathrm{a})$ \\
\hline Portugal & 3.5 & 3.0 & 2.1 & 5.2 & 4643 & -7074 \\
\hline Espanha & 4.2 & 6.9 & 1.5 & 5.2 & 9029 & 5448 \\
\hline Total & 100.0 & 100.0 & 100.0 & 100.0 & & \\
\hline
\end{tabular}

Fonte: INTERLAINE

a) 1992

Uma outra característica importante é que aqueles países trocam, preferencialmente, entre si, ou seja, elegem-se como principais parceiros para as trocas intra-UE. Assim, se tivermos em conta a intensidade das trocas internas, podemos formar um grupo que se distingue bem dos outros. Por outro lado, a divisão territorial do trabalho entre eles é clara, cabendo a cada um uma função específica ao longo da fileira têxtil de lanifícios: a França domina a fase inicial, a dos penteados; a Alemanha a fase intermédia, a da fiação; enquanto a Itália domina a final, ou seja, a tecelagem (quadro IV). 


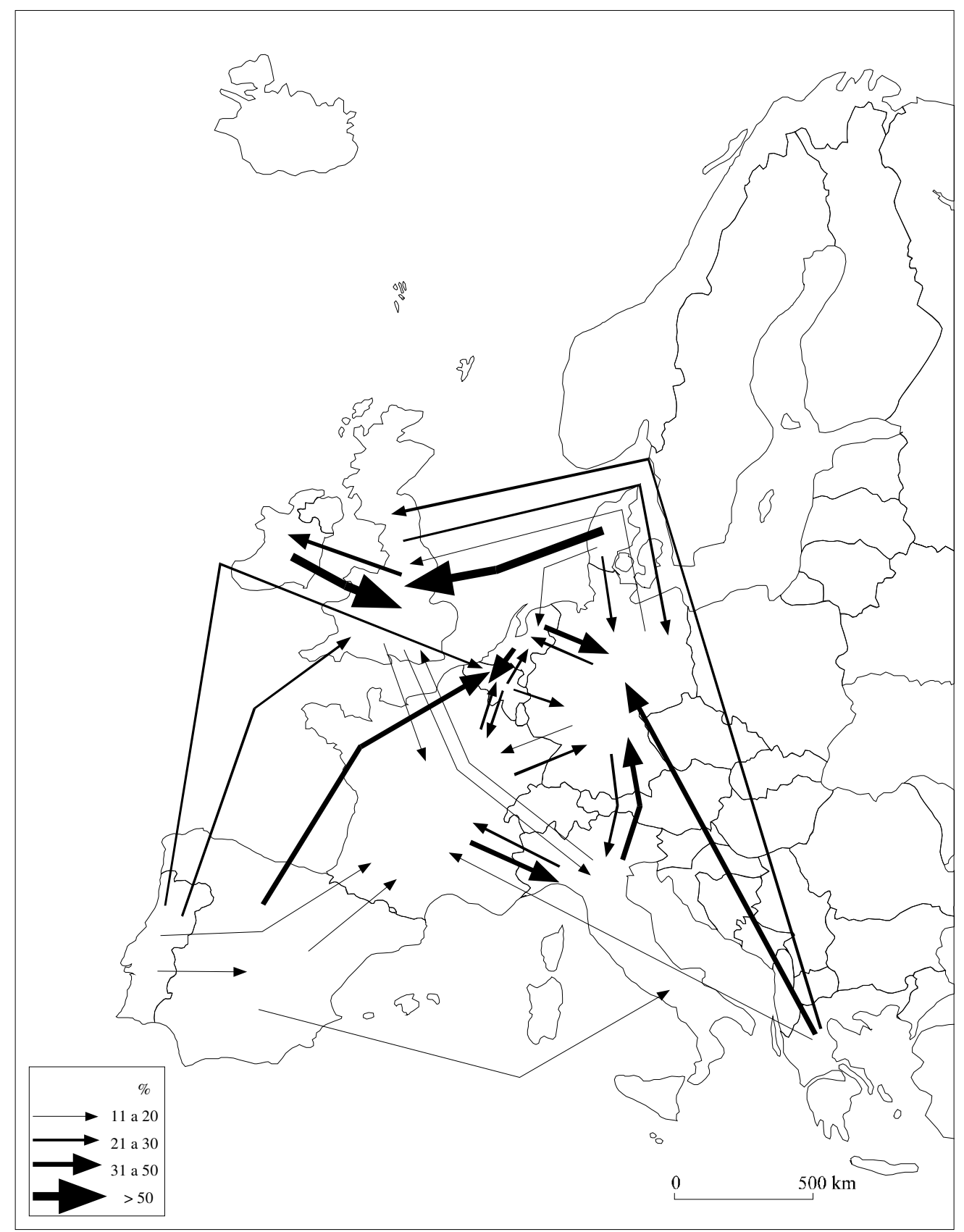

Fonte: INTERLAINE

Figura $2 \mathrm{a}$ - Principais destinos das exportações de lanifícios em percentagem do total de exportações do país de origem, 1988.

Figure $2 \mathrm{a}-$ Wool textile export markets in \% of the national total exports, 1988. 


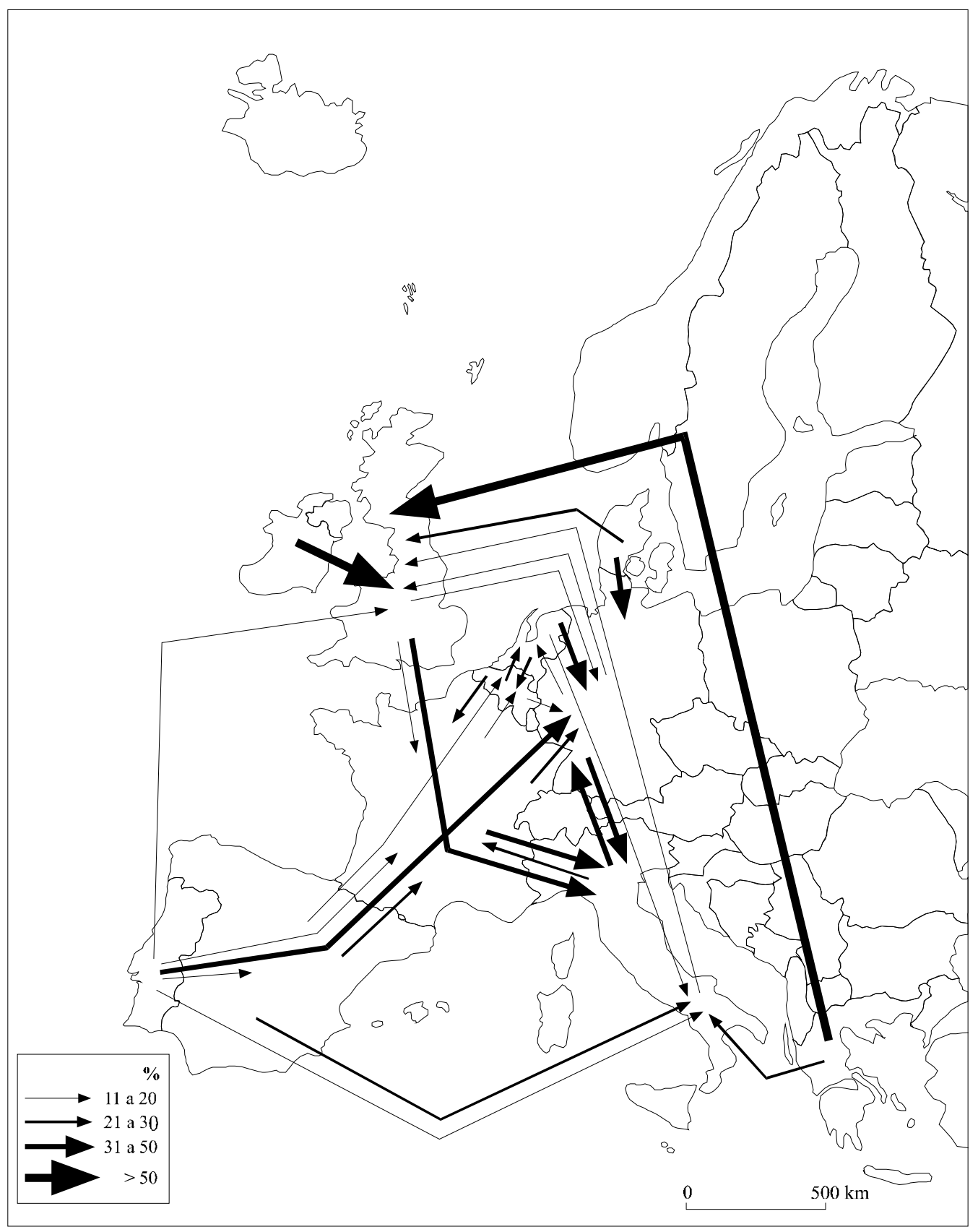

Fonte: INTERLAINE

Figura $2 b$ - Principais destinos das exportações de lanifícios em percentagem do total de exportações do país de origem, 1994.

Figure $2 b-$ Wool textile export markets in \% of the national total exports, 1994 . 
De uma maneira geral, entre 1988 e 1994, acentua-se o peso do principal destino e apenas um ou dois países consomem mais de metade do volume de exportações de um outro. Reforça-se assim, ao mesmo tempo, a coesão deste núcleo central e a marginalização dos outros países no espaço produtivo da UE.

Quadro IV - Principais exportadores intra-UE e principais parceiros em 1988, 1992 e 1994 Table IV - Main Intra-EU exporters, 1988, 1992 and 1994

\begin{tabular}{|c|c|c|c|c|c|c|c|c|}
\hline Produto & $\begin{array}{c}\text { País Ex- } \\
\text { portador (1) }\end{array}$ & $\begin{array}{c}1988 \\
(\%)\end{array}$ & $\begin{array}{l}1992 \\
(\%)\end{array}$ & $\begin{array}{c}1994 \\
(\%)\end{array}$ & $\begin{array}{l}\text { País de Des- } \\
\text { tino (2) }\end{array}$ & $\begin{array}{c}1988 \\
(\%)\end{array}$ & $\begin{array}{c}1992 \\
(\%)\end{array}$ & $\begin{array}{c}199 \\
4 \\
(\%)\end{array}$ \\
\hline Penteados de Lã & França & 56.8 & 50.2 & 51.0 & Itália & 49.3 & 53.0 & 55.3 \\
\hline Fios de Lã Cardada & $\begin{array}{r}\text { Reino } \\
\text { Unido } \\
\text { Irlanda }\end{array}$ & $\begin{array}{l}25.5 \\
16.7\end{array}$ & $\begin{array}{l}34.8 \\
12.9\end{array}$ & a) & $\begin{array}{r}\text { Irlanda } \\
\text { Reino Unido }\end{array}$ & $\begin{array}{l}43.4 \\
96.8\end{array}$ & $\begin{array}{l}55.3 \\
93.7\end{array}$ & a) \\
\hline Fios de Lã Penteados & Alemanha & 43.6 & 41.1 & 45.9 & Itália & 57.7 & 55.3 & 59.4 \\
\hline $\begin{array}{l}\text { Fios com }+ \text { de } 85 \% \text { Sin- } \\
\text { téticos misturados com } \\
\text { lã }\end{array}$ & $\begin{array}{r}\text { Itália } \\
\text { Benelux }\end{array}$ & $\begin{array}{l}33.0 \\
17.2\end{array}$ & $\begin{array}{l}24.0 \\
18.2\end{array}$ & 36.7 & $\begin{array}{r}\text { França } \\
\text { Alemanha } \\
\text { França } \\
\text { Alemanha }\end{array}$ & $\begin{array}{r}25.7 \\
4.9 \\
25.8 \\
27.7 \\
\end{array}$ & $\begin{array}{l}30.4 \\
29.2 \\
30.2 \\
27.2\end{array}$ & $\begin{array}{l}30.9 \\
26.2 \\
26.8 \\
23.8 \\
\end{array}$ \\
\hline Tecidos de Lã Cardada & Itália & 79.4 & 79.3 & 80.9 & Alemanha & 42.5 & 46.7 & 47.0 \\
\hline Tecidos de Lã Pentados & Itália & & 43.1 & 50.3 & $\begin{array}{r}\text { Alemanha } \\
\text { França } \\
\end{array}$ & $\begin{array}{l}45.6 \\
20.9 \\
\end{array}$ & $\begin{array}{l}45.8 \\
19.7 \\
\end{array}$ & $\begin{array}{l}46.6 \\
25.2 \\
\end{array}$ \\
\hline $\begin{array}{l}\text { Tecidos Sintéticos } \\
\text { Misturados com Lã }\end{array}$ & $\begin{array}{r}\text { Alemanha } \\
\text { França }\end{array}$ & $\begin{array}{l}18.9 \\
20.7\end{array}$ & $\begin{array}{l}22.4 \\
18.6 \\
\end{array}$ & $\begin{array}{l}15.9 \\
15.7\end{array}$ & $\begin{array}{r}\text { Alemanha } \\
\text { Reino Unido } \\
\text { França } \\
\text { Holanda } \\
\text { Alemanha }\end{array}$ & $\begin{array}{l}20.4 \\
36.8 \\
24.9 \\
50.3 \\
28.8 \\
\end{array}$ & $\begin{array}{l}32.7 \\
21.9 \\
19.4 \\
38.8 \\
34.3\end{array}$ & $\begin{array}{l}40.0 \\
20.0 \\
16.8 \\
44.0 \\
37.6 \\
\end{array}$ \\
\hline
\end{tabular}

Fonte: INTERLAINE.

(1) Peso do país no total das exportações intra UE

(2) Peso do país no total das exportações do país exportador.

a) Nas Estatísticas de 1994 não surgem as exportações com destino à Irlanda pelo que não é possível avaliar correctamente a estrutura das trocas de fios de lã cardada.

O Reino Unido, por seu lado, é o principal exportador de fios de lã cardada, que orienta quase exclusivamente para a Irlanda. De certa maneira, formam um outro grupo, pois a intensidade das trocas entre eles é muito elevada. O Reino Unido é o principal abastecedor da Irlanda em fios e tecidos, e por sua vez é o seu mais importante parceiro comercial para todos os produtos. A ligação com o exterior, nomeadamente com o primeiro grupo, é feita pelo Reino Unido, uma vez que a Irlanda poucas trocas realiza com os outros países (fig. 2a e 2b). A França, que era em 1988 um importante destino das suas exportações, em 1994 já ocupa um lugar irrelevante. Mas enquanto a Irlanda reforça a sua dependência do Reino Unido, este procura diversificar e consolidar as trocas com outros parceiros, nomeadamente com a França e com a Itália, que já representam o mesmo peso que a Irlanda como destino dos seus produtos. $\mathrm{O}$ Reino Unido, que já foi o primeiro produtor mundial de lanifícios, procura recuperar um papel mais activo aproximando-se dos países que constituem o núcleo central desta indústria e que dominam o tráfego na UE. Este esforço foi recompensado pela redução do deficit da balança comercial, conseguido com um aumento das exportações e diminuição do volume das importações.

A proximidade geográfica pode ter sido um dos factores que contribuiu para a reorientação das exportações dinamarquesas do Reino Unido para a Alemanha. Por outro lado, a Grécia estreita os laços comerciais com um mercado longínquo (à escala da UE) vendendo mais de $60 \%$ das suas exportações ao Reino Unido, ao mesmo tempo que se reduz o peso da Alemanha.

Quanto aos países ibéricos, a Bélgica era, em 1988, um valioso destino das exportações para ambos. Mas em 1994, como se pode observar nas figuras, a Espanha opta por reforçar as trocas com a França e com a Itália, enquanto o nosso país elege a Alemanha como principal destino. 
Este país recebeu, em 1994, 32\% do total das exportações portuguesas, enquanto em 1988 pouco ultrapassou os $7 \%$.

As empresas portuguesas parecem estar a desistir de mercados tradicionais, como o belga e o inglês, em favor de outros mais dinâmicos, como o alemão, o que é positivo. Porém, têm que ter consciência que este é um mercado sujeito a forte pressão quer por parte de todos os produtores da UE, quer pelos do Leste da Europa, alguns com tradição na indústria de lanifícios e geograficamente mais próximos.

A conquista e consolidação de novos destinos dentro da UE, só conseguida com a mudança de atitudes por parte das empresas nacionais e com um maior investimento na inovação do produto e na comercialização, é essencial para a sobrevivência dos lanifícios portugueses, já que somos o país que mais conta com este mercado para colocar a sua produção. Desde 1989, a reorientação das nossas exportações para o espaço económico europeu é nítida, e sendo questionável se uma tal dependência representa um factor favorável, o certo é que ela tem vindo a agravar-se.

Contudo, a evolução recente não lhe tem sido muito favorável. As exportações portuguesas, que mostraram um crescimento até 1988 , desde esse ano têm vindo sempre a reduzir-se. A nossa balança comercial passou a ser negativa nos penteados (que importamos sobretudo da França e da Itália), nos fios de lã cardada (da Itália e do Reino Unido) e nos fios com mais de 85\% de fibras sintéticas (maior crescimento com proveniência da França, Bélgica e Holanda). No caso dos tecidos, o maior volume de importação deve-se aos tecidos de lã cardada (sendo a Itália responsável por mais de metade das importações) e aos tecidos de lã penteada (repartindo a Itália e a Alemanha uma posição semelhante na origem destas importações). Apesar de os produtos intermédios dominarem a estrutura das importações (em 1988 representavam 55\% e em 1994 69\% do total), as dos tecidos cresceram significativamente desde 1986. Esta situação resultou, em grande parte, da incapacidade da indústria de lanifícios nacional para responder à dinâmica da procura interna por parte da indústria de vestuário. Por outro lado, apesar do incremento da produção de vestuário, esta está fortemente dependente de encomendas provenientes do estrangeiro. Na maior parte das vezes, no nosso país apenas é incorporada mão-de-obra, enquanto a matéria prima ou os produtos intermédios são impostos pela empresa que subcontrata, sendo assim fraco o estímulo para a modernização da indústria têxtil nacional (PIRES, 1995). Com efeito, a produção de tecidos para vestuário começou a decrescer logo em 1986, a de fios cardados desde 1987 e a de fios penteados desde 1990.

\section{2 - TROCAS EXTRA-UE}

\section{1 - Exportações}

As exportações de lanifícios da UE começaram a recuperar em 1988, após um período de quebra, ao mesmo tempo que se alterava a estrutura: os produtos de menor valor acrescentado (fios com mistura «pobre» de lã e fios sintéticos e artificiais) vão cedendo o lugar aos mais elaborados, caso dos tecidos penteados, provavelmente consequência do aumento da concorrência no mercado internacional (fig. 3 e quadro V). Enquanto em 1988 eram os produtos intermédios que dominavam a estrutura das exportações, em 1994 esse lugar pertence aos produtos finais. 


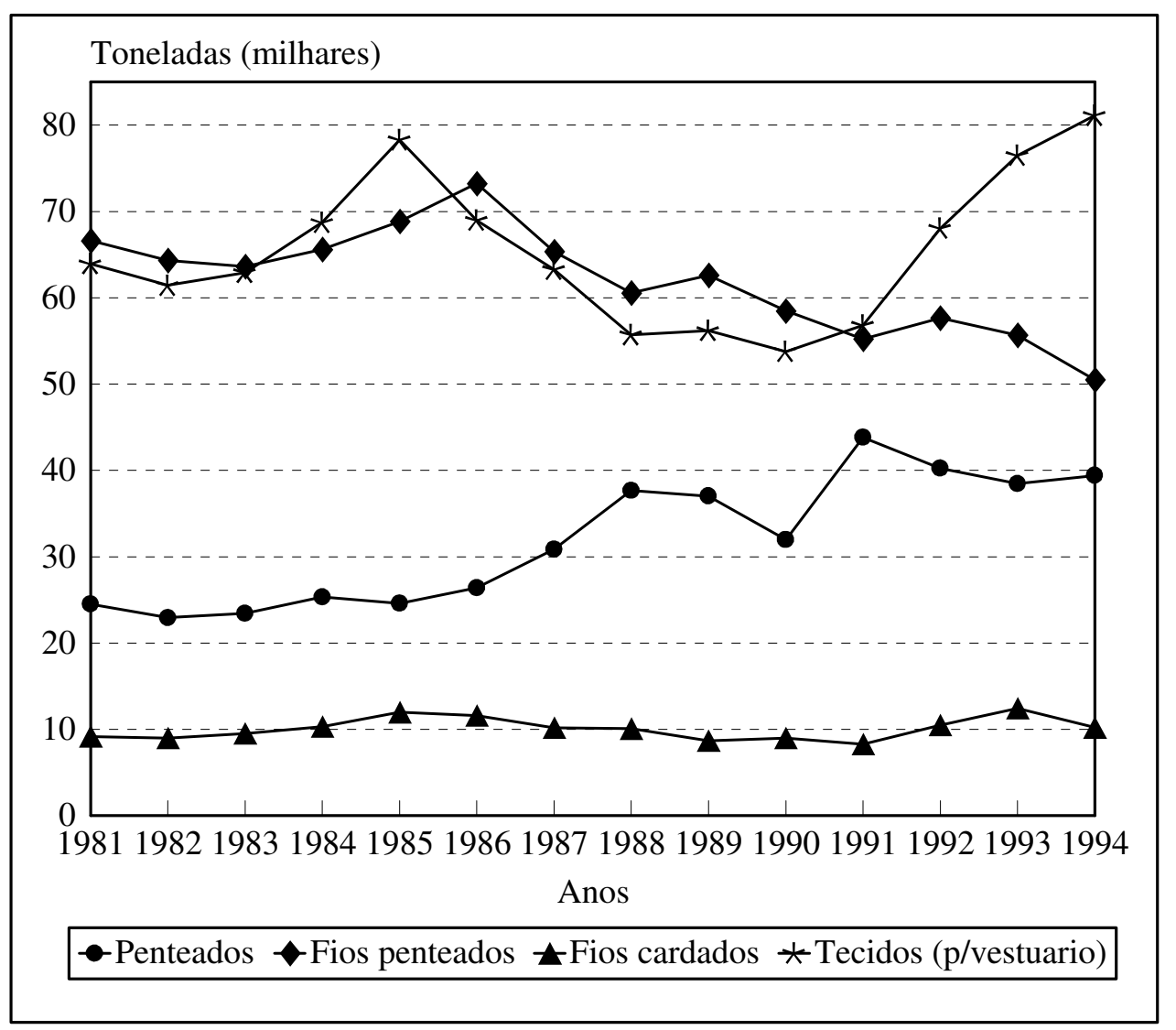

Fonte: INTERLAINE

Os valores das exportações referem-se aos seguintes países:

Alemanha, Bélgica, França, Itália, Holanda, Reino Unido.

Irlanda, Dinamarca e Grécia desde 1982. Espanha e Portugal desde 1986.

Figura 3 - Exportação de lanifícios extra-UE.

Figure 3 - Wool textile exports to non-EU markets.

Quadro V - Estrutura das exportações de lanifícios da UE, 1988 e 1994

Table V - EU wool textile exports structure, 1988-1994

\begin{tabular}{|l|r|r|r|r|}
\hline & 1988 (Ton.) & $\%$ & 1994 (Ton.) & $\%$ \\
\hline Penteados & 37663 & 23.0 & 39414 & 21.7 \\
\hline Fios Penteados & 60548 & 36.9 & 50494 & 27.9 \\
\hline Fios Cardados & 10087 & 6.2 & 10211 & 5.6 \\
\hline Tecidos de Lã & 38043 & 23.2 & 65242 & 36.0 \\
\hline Tec. Sint. Mist. de Lã & 17649 & 10.7 & 15859 & 8.8 \\
\hline Total Exp. UE & 163990 & 100.0 & 181220 & 100.0 \\
\hline
\end{tabular}

Fonte: INTERLAINE.

A balança comercial da UE permanece, no entanto, positiva (quadro VI). Mas se o saldo é confortável no caso dos tecidos e tem vindo a aumentar nos fios cardados, o inverso está a acontecer nos fios com mais de $85 \%$ de sintéticos e nos penteados. Por enquanto, a exportação de produtos com maior valor acrescentado (tecidos), que se prevê continue a aumentar, consegue superar a importação de produtos do início da fileira de lanifícios, cujo crescimento também é de esperar.

Por outro lado, o envolvimento da Alemanha na produção de penteados tem contribuído para a redução do deficit da balança comercial deste produto. 
Quadro VI - Balança comercial da UE de lanifícios, 1981-1994

Table VI - EU Wool textile trade balance, 1981-1994

\begin{tabular}{|l|r|r|r|r|r|}
\hline & 1981 & 1984 & 1987 & 1990 & 1994 \\
\hline Penteados & -12705 & -14656 & -3192 & -3520 & -1617 \\
\hline Fios Penteados & 23144 & 2248 & 5598 & 2148 & -244 \\
\hline Fios + 85\% Sint. & & 6273 & -2266 & 9842 & -19587 \\
\hline Fios Cardados & 4839 & 3503 & 8686 & 7769 & 8357 \\
\hline Tecidos de Lã & 30353 & 35910 & 35578 & 37628 & 56754 \\
\hline Tec. Sint. Mist. Lã & 24187 & 22110 & 20635 & 8428 & 12642 \\
\hline
\end{tabular}

Fonte: INTERLAINE.

Se o aumento da concorrência no mercado global dos produtos menos valorizados explica a especialização da UE na exportação de tecidos, esta não será a única causa, ou mesmo a mais importante, a justificá-la. Ela decorre, igualmente, da estratégia desenvolvida pelas empresas de vestuário, que exportam produtos intermédios para países com baixos custos salariais importando, após as fases de acabamento, os produtos finais (PIRES, 1996). Também uma parte das exportações de fios pode resultar da mesma situação.

O leque dos principais exportadores é muito restrito e mantém-se sem alterações. Dele fazem parte a Itália e a Alemanha, que repartem entre si a maior fatia em quase todos os produtos. Em 1988, ainda surge a Bélgica em segundo lugar nas exportações de fios cardados, mas é substituída pela Itália. O mesmo acontece ao Reino Unido, que apesar de continuar a liderar as exportações de fios cardados, cede o seu lugar à Alemanha nos penteados. A Espanha, por seu lado, mantém-se como principal exportador de cobertores (quadro VII).

Ao longo do último decénio, os países reforçam a sua posição nos produtos para os quais já haviam adquirido vantagens competitivas no mercado mundial. Assim, a Itália aumenta o seu peso nas exportações de tecidos cardados, a Alemanha exporta sobretudo tecidos de lã com mistura de sintéticos, o Reino Unido especializa-se na exportação de fios de lã cardada e a Espanha na de cobertores.

Quadro VII - Principais exportadores de lanifícios da UE, 1987-1994

Table VII - Main EU exporters, 1987-1994

\begin{tabular}{|l|l|r|l|r|l|r|}
\hline Produto & \multicolumn{1}{|c|}{1987} & \% nas Exp. UE & \multicolumn{1}{|c|}{1990} & \% nas Exp. UE & \multicolumn{1}{|c|}{1994} & $\%$ nas Exp. UE \\
\hline \multirow{2}{*}{ Penteados } & R. Unido & 32.9 & R. Unido & 31.5 & Alemanha & 44.4 \\
& França & 30.0 & França & 31.0 & R. Unido & 26.3 \\
\hline \multirow{2}{*}{ Fios Cardados } & R. Unido & 36.9 & R. Unido & 34.1 & R. Unido & 43.6 \\
& Bélgica & 16.3 & Itália & 17.5 & Itália & 27.7 \\
\hline Fios Penteados & Itália & 32.2 & Alemanha & 32.6 & Itália & 45.3 \\
& Alemanh & 23.7 & Itália & 30.7 & Alemanha & 22.4 \\
\hline Fios com + de 85\% Sin- & Itália & 34.6 & Itália & 27.3 & Alemanha & 31.5 \\
téticos misturados com lã & Alemanh & 25.3 & Alemanha & 26.7 & Itália & 24.3 \\
\hline \multirow{2}{*}{ Tecidos Cardados } & Itália & 40.5 & Itália & 45.0 & Itália & 48.9 \\
& Alemanh & 29.3 & Alemanha & 33.7 & Alemanha & 31.5 \\
\hline Tecidos Penteados & Itália & 50.3 & Itália & 31.5 & Itália & 42.0 \\
& Alemanh & 19.3 & Alemanha & 22.2 & Alemanha & 31.1 \\
\hline Tecidos com Sintéticos & Itália & 71.0 & Alemanha & 40.6 & Alemanha & 44.1 \\
misturados com lã & Alemanh & 13.8 & Itália & 31.3 & Itália & 33.4 \\
\hline Cobertores & Espanha & 52.5 & Espanha & 35.6 & Espanha & 50.4 \\
& Itália & 21.8 & Itália & 26.9 & Itália & 21.4 \\
\hline
\end{tabular}

Fonte: INTERLAINE. 
Mas enquanto alguns produtos italianos têm vindo a perder competitividade no mercado global, o contrário se passa com os da Alemanha. Este país consegue reforçar a sua posição como exportador de lanifícios e deu o principal contributo para o incremento das exportações da UE, enquanto a Itália manteve sensivelmente o mesmo valor de 1989. Sendo assim, o principal concorrente dos lanifícios italianos é um outro país da UE: observe-se a alteração cíclica na posição de liderança nas exportações de fios penteados entre a Itália e a Alemanha, ou a conquista desse lugar pelo segundo país, no caso dos fios com mais de $85 \%$ de sintéticos e nos tecidos de lã com mistura de sintéticos.

A manter-se esta tendência de evolução, as posições da Alemanha e da Itália tenderão a equilibrar-se, embora o papel dominante ainda pertença a esta última.

Entre 1988 e 1994, as principais alterações nas exportações da UE são, por um lado, a redução do peso dos destinos mais importantes e, por outro, a tendência para a substituição dos países industrializados por países do Leste da Europa e novos países industrializados, quer nos tecidos de lã cardada quer nos de lã penteada (quadro VIII).

Quadro VIII - Exportação de tecidos da UE para alguns países, em 1988 e 1993 Table VIII - EU fabric exports

\begin{tabular}{|c|c|c|c|c|c|c|c|}
\hline \multicolumn{4}{|c|}{ Tecidos Penteados } & \multicolumn{4}{|c|}{ Tecidos Cardados } \\
\hline \multicolumn{2}{|c|}{1988} & \multicolumn{2}{|c|}{1994} & \multicolumn{2}{|c|}{1988} & \multicolumn{2}{|c|}{1994} \\
\hline País & $\begin{array}{c}\text { Peso no } \\
\text { total das } \\
\text { Export. }\end{array}$ & País & $\begin{array}{l}\text { Peso no } \\
\text { total das } \\
\text { Export. }\end{array}$ & País & $\begin{array}{l}\text { Peso no } \\
\text { total das } \\
\text { Export. }\end{array}$ & País & $\begin{array}{l}\text { Peso no } \\
\text { total das } \\
\text { Export. }\end{array}$ \\
\hline Japão & 20.2 & Japão & 9.7 & Jugoslávia & 15.6 & Polónia & 11.9 \\
\hline Jugoslávia & 12.3 & Polónia & 7.3 & Est. Unidos & 12.4 & Roménia & 7.4 \\
\hline $\begin{array}{l}\text { Est. } \\
\text { Unidos }\end{array}$ & 10.7 & Est. Unidos & 6.2 & Japão & 8.9 & Hong Kong & 7.1 \\
\hline Suiça & 7.1 & Hong Kong & 5.5 & Áustria & 8.8 & Japão & 5.5 \\
\hline Áustria & 6.5 & Marrocos & 5.4 & Hungria & 5.8 & Áustria & 3.7 \\
\hline Canadá & 4.9 & Hungria & 5.0 & Roménia & 5.0 & Hungria & 3.3 \\
\hline $\begin{array}{l}\text { Hong } \\
\text { Kong }\end{array}$ & 4.8 & Roménia & 4.9 & Polónia & 4.6 & Formosa & 3.1 \\
\hline
\end{tabular}

Como foi referido, esta tendência poderá estar relacionada com o aumento do tráfego de aperfeiçoamento passivo. Esta é uma das estratégias delineadas pela indústria do vestuário da UE, que lhe permite manter a qualidade do produto final, utilizando para isso produtos intermédios obtidos na UE, ao mesmo tempo que reduz os custos de produção, subcontratando as fases mais intensivas em força de trabalho em países próximos e com baixos custos salariais.

Apesar de o Japão manter o lugar de principal destino dos tecidos penteados, o volume de exportações para este mercado de difícil acesso reduz-se, enquanto com a Polónia, Marrocos ou a Roménia, por exemplo, cresce de forma significativa nestes seis anos. Outros países que passam a receber tecidos penteados da UE são: a Croácia, a Coreia do Sul, a Eslovénia e a Tunísia, significando cada um deles entre $4.7 \%$ a $3.2 \%$ do total, o que corrobora a hipótese de se tratar apenas da saída temporária de produtos intermédios reimportados após a confecção.

A situação é semelhante para os tecidos cardados, mas neste caso a Polónia e a Roménia atingem rapidamente os lugares do topo. O Japão e a Áustria permanecem como principais clientes do grupo dos países industrializados, mas representando menos de $10 \%$ das exportações.

O facto de alguns países do Norte de África se salientarem como importadores de produtos de qualidade, parece contradizer a ideia segundo a qual lhes estaria reservada a subcontratação de artigos de qualidade menor. Contudo, esta alteração é recente pois, tanto em finais dos anos setenta, como em finais dos anos oitenta, o seu peso nas importações de tecidos era 
negligenciável. Só a Tunísia surgia, nessas décadas, entre os principais importadores, mas de fios misturados com mais de $85 \%$ de sintéticos, sem dúvida destinados à confecção de tecidos para abastecer o mercado interno. $\mathrm{O}$ facto de importarem, agora, produtos intermédios de qualidade pode relacioná-los com a melhoria do seu posicionamento nas redes de subcontratação. Pelo contrário, a Turquia que em 1993 recebia 5\% das exportações de tecidos de lã penteada e $4.5 \%$ dos de lã cardada, tem cada vez menos importância como destino das exportações, o que pode decorrer ou de uma melhoria da produção interna diminuindo a dependência da indústria têxtil e do vestuário do exterior, ou de uma subida dos salários que tornaria este país menos atractivo para o tráfego de aperfeiçoamento passivo, nomeadamente quando comparado com os países do Leste da Europa com os quais a UE estabeleceu relações privilegidadas.

\section{2 - Importações}

A UE importa maioritariamente produtos intermédios, como os penteados e os fios penteados, enquanto os tecidos continuam a ter pouco peso na estrutura das importações (quadro IX e fig. 4). Por outro lado, pode observar-se que para todos os segmentos da fileira se reduz a importância da principal origem nas importações, e que o leque de países, do qual faziam parte, em 1988, tanto países industrializados como novos países industrializados, tem vindo a modificar-se pois surgem agora com maior relevância estes últimos bem como países do Leste da Europa.

Quadro IX - Estrutura das importações de lanifícios da UE, 1988 e 1994

Table IX - EU wool textile import structure, 1988-1994

\begin{tabular}{|l|r|r|r|r|}
\hline & 1988 (Ton.) & $\%$ & 1994 (Ton.) & $\%$ \\
\hline Penteados & 27314 & 32.1 & 41031 & 32.9 \\
\hline Fios Penteados & 47838 & 56.1 & 70265 & 56.3 \\
\hline Fios Cardados & 1238 & 1.5 & 1854 & 1.5 \\
\hline Tecidos de Lã & 6005 & 7.0 & 8488 & 6.8 \\
\hline Tec. Sint. Mist. Lã & 2845 & 3.3 & 3217 & 2.5 \\
\hline Total Imp. UE & 85240 & 100.0 & 124855 & 100.0 \\
\hline
\end{tabular}

Fonte: INTERLAINE. 


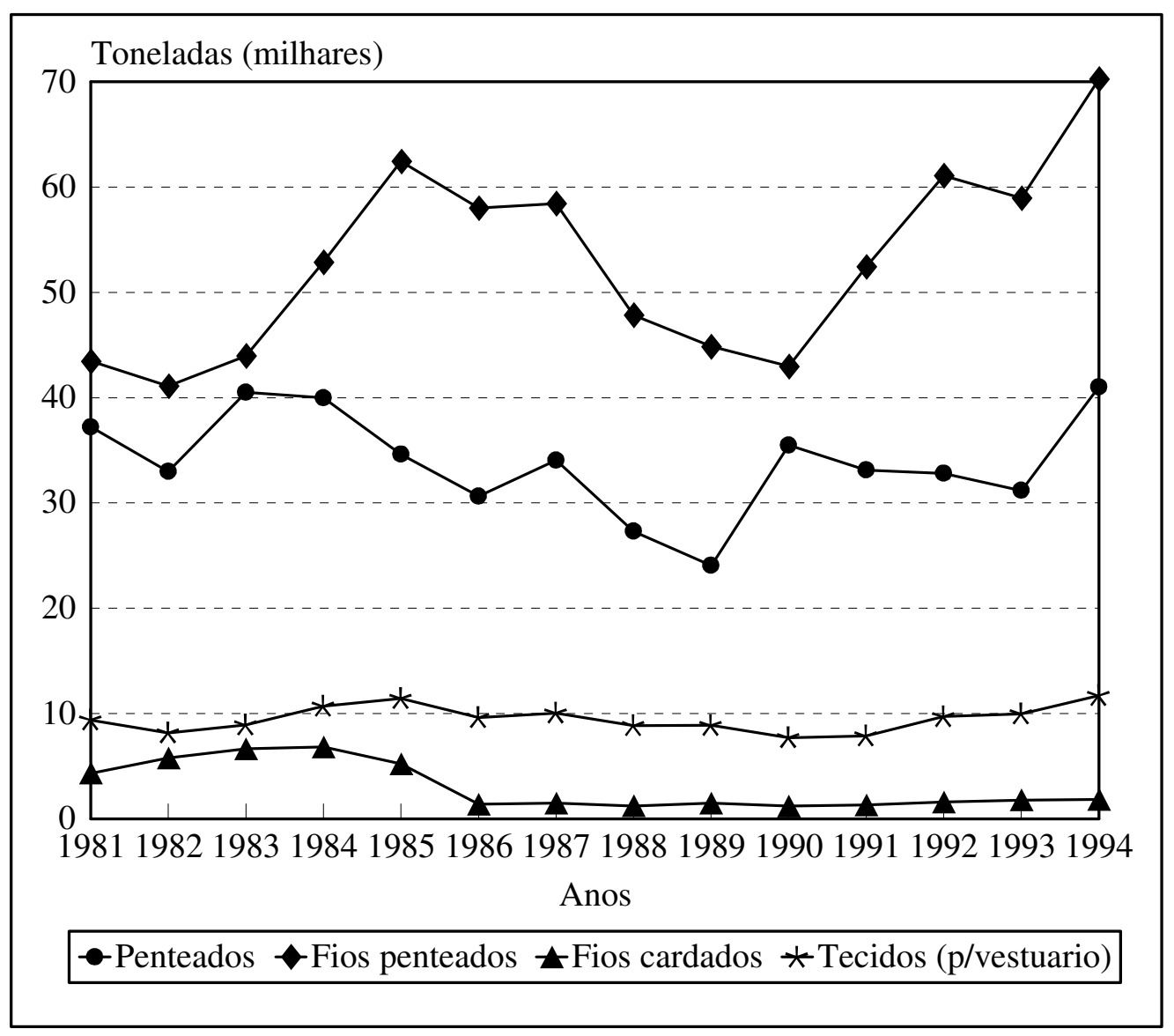

Fonte: INTERLAINE

Os valores das importações referem-se aos seguintes países:

Alemanha, Bélgica, França, Itália, Holanda, Reino Unido.

Irlanda, Dinamarca e Grécia desde 1982. Espanha e Portugal desde 1986.

Figura 4 - Importação de lanifícios extra-UE, 1981-1994.

Figure 4 - Wool textile imports from non-EU countries, 1981-1994.

Os países produtores de lã venderam-na em bruto durante muito tempo mas procuram, actualmente, desenvolver algumas das fases de tratamento no país, exportando um produto com maior valor acrescentado. Assim, em lugar de lã em bruto, países como o Uruguai, a África do Sul ou a Argentina exportam penteados (quadro X). A França, que se tinha especializado na sua produção, está a sofrer com o surgimento destes novos países produtores, que tiram partido do facto de terem empresas mais recentes, normalmente bem equipadas e ainda de baixos custos de mão-de-obra. A perda da sua competitividade traduz-se, como vimos, na redução do volume de produção, ao mesmo tempo que crescem as importações extra-UE. 
Quadro X - Principais origens das importações de lanifícios da UE, 1988 e 1994

Table X - EU wool textile imports, 1988-1994

\begin{tabular}{|l|l|r|l|r|}
\hline Produtos & \multicolumn{1}{|c|}{1988} & \% nas Import. UE & \multicolumn{1}{|c|}{1994} & \% nas Import. UE \\
\hline Penteados & Uruguai & 30.1 & Uruguai & 31.8 \\
\hline & África Sul & 21.0 & África Sul & 13.8 \\
\hline & Brasil & 18.0 & Brasil & 11.3 \\
\hline Fios Cardados & Turquia & 29.5 & Finlândia & 28.2 \\
\hline & Finlândia & 15.7 & Áustria & 17.3 \\
\hline Fios Penteados & Suíça & 68.6 & Polónia & 14.7 \\
\hline & Áustria & 11.0 & Índia & 14.0 \\
\hline Fios + 85\% Sint. & Coreia Sul & 22.6 & Indonésia & 17.9 \\
\hline & Turquia & 16.8 & Turquia & 11.6 \\
\hline Tecidos Cardados & Áustria & 36.4 & Polónia & 27.9 \\
\hline & & & Áustria & 12.1 \\
\hline Tecidos Penteados & Suíça & 26.5 & Uruguai & 14.0 \\
\hline & China & 17.0 & Rep. Checa & 10.4 \\
\hline Tecidos de Sint. & Checoslováquia & 37.2 & Rep. Checa & 28.5 \\
\hline Mist. com Lã & Áustria & 22.9 & Áustria & 9.3 \\
\hline Cobertores & Jugoslávia & 28.5 & Turquia & 18.1 \\
\hline & Checoslováquia & 25.8 & Rep. Checa & 18.0 \\
\hline
\end{tabular}

Fonte: INTERLAINE.

Do mesmo modo, a Nova Zelândia já conseguiu atingir uma posição de destaque na exportação de fios cardados para a UE, apesar ela ser dominada por dois países Europeus tal como o Uruguai nos tecidos penteados.

Mas o que mais se destaca nesta estrutura são os fios penteados. Estes são indispensáveis para a produção de tecidos e malhas e como a sua produção tem vindo a baixar (consequência sobretudo da evolução da produção na Alemanha e apesar do contributo da Espanha) é necessário importá-los. Ao contrário do que acontece com os penteados, as importações tinham origem, na sua maior parte, em países europeus - Suíça e Áustria - mas em 1994 eles foram substituídos por países onde os custos de produção são menores.

\section{CONCLUSÃO}

$\mathrm{Na}$ indústria europeia de lanifícios existe uma clara diferenciação entre os países, quer quanto à especialização produtiva, quer quanto à posição na estrutura comercial. Enquanto a Itália e a Alemanha já têm definido o seu papel, competindo de forma aguerrida pelo lugar cimeiro, a emergência de um novo padrão produtivo exigiria, por parte dos outros países, um enorme investimento na criatividade (onde dominam as empresas italianas) e na eficiência empresarial (na qual se destacam as empresas alemãs). Se esse esforço não for feito, a hegemonia daqueles países não será atenuada e a fragmentação do espaço produtivo entre países do centro, onde se poderão integrar a França e o Reino Unido, e da periferia permanecerá.

Portugal, que faz parte do segundo grupo, tem visto o deficit da balança comercial a agravar-se. Apesar disso, somos um dos países em que o comércio intra-UE é fundamental para a sobrevivência da indústria de lanifícios, pois este representava, em 1994, 83.3\% do total das nossas exportações, enquanto em 1988 esse valor era 76\%. Sendo assim, ou as empresas portuguesas procuram novos destinos extra-UE que, podendo ser menos valorizados também estarão sob menor pressão, ou aprofundam as relações com os parceiros da UE, em particular com os mercados mais apetecíveis como o alemão, e nesse caso terão que investir na revalorização dos seus produtos.

Há que estar atento, também, à evolução da indústria têxtil em países potenciais concorrentes, nomeadamente os do Leste da Europa, alguns dos quais com tradição na 
produção de lanifícios e que naturalmente procuram compensar no mercado da UE a perda dos seus antigos mercados.

\section{BIBLIOGRAFIA}

AmIN, A. (1989) - Flexible Specialization and Small Firms in Italy: myths and realities. Antipode, 21 (1): 13-34.

BAGNASCO, A. (1989) - Développement régional, société locale et économie diffuse. in M. MARUANI, E. REYNAUD e C. Romani (ed.). La Flexibilité en Italie, Syrus/Alternatives, Paris.

BeCATtinI, G. (1992) - Le district industriel: milieu créatif. Espaces et Sociétés, 66-67: 147-164.

CHARBIT, C. et al (1991) - Sous-traitance et intégration industrielle européenne. Révue d'Économie Industrielle, 55: 178-189.

Consolati, L. (1983) - Il sistema tessile-laniero della val Gandini. in G. Garofoli (ed.). Industrializzazione Difusa in Lombardia, Franco Angeli Editore, Milão.

CONTINI, B (1988) - Grandi e piccole imprese industriali in Itália: dinamica e performance negli anni'80 a confronto. Moneta e Credito, XLI, (163): 331-360.

FINE (1995) - Competitiveness in the textiles and clothing districts of Europe - a strategy. Fashion Industry Network Europe.

INTERLAINE (1977, 1988, 1992, 1993 e 1994) - L'Industrie Lanière de la Comunauté Économique Européenne. Bruxelas.

PIRES, I. (1994) - A Teia e a Trama na Geografia das Indústrias Têxtil e do Vestuário. Dissertação de Doutoramento em Geografia Humana, Faculdade de Letras de Lisboa.

PIRES, I. (1995) - Reestruturação de uma Região Industrial Tradicional: a Beira Interior e a indústria de lanifícios. in C. CAVACo (ed.). As Regiões de Fronteira, Inovação e Desenvolvimento na Perspectiva do Mercado Único Europeu. EPRU no 43 , Centro de Estudos Geográficos, Lisboa.

PIRES, I. (1996) - As Indústrias Têxtil e do Vestuário na UE. Os Novos Factores de Competitividade. Finisterra. Revista Portuguesa de Geografia, XXXI (59).

SCHEFFER, M. (1994) - The Changing Map of European Textiles. OETH, Bruxelas. 